\title{
Price management system in the field of forming the value of eco-friendly commercial products
}

\author{
Natalya Cherner $^{1, *}$ \\ ${ }^{1}$ MGIMO University, 143007, (Odintsovo branch) Moscow region, Odintsovo, Novo-Sportivnaya \\ str., 3
}

\begin{abstract}
The purpose of this study is to develop a methodology for justifying and accepting prices for supplied and purchased commercial products, based on an analysis of the functioning of price management at high-tech production enterprises at the micro-, meso- and micro-levels. A conceptual interpretation problem is presented - either to organize and implement a unified price representation, or to create a unique management toolkit for each scheme. It is considered how it is possible to localize specialized management: in the area under consideration - as price management for various organizational and institutional levels of management, including the case of corporate groupings, such as Russian high-tech holdings.
\end{abstract}

\section{Introduction}

One of the most important spheres of management at the micro-, meso- and macro- levels is the sphere of formation (justification and acceptance) of prices for commercial products, both supplied and purchased from production suppliers. Indeed, it is commonplace that, depending on the amount of revenue (for suppliers) or the amount of costs (for customers), the financial and economic results of any subject of legal relations (individuals, legal entities or other persons such as states) will vary significantly. This statement is applicable to any known pricing scheme, of which there are more than fifty now. However, quite often, along with the usual price compensation schemes, others are used - among the most widespread, one should mention, first of all, the tariff and deduction schemes, and the deduction scheme has quite a few versions. By the way, the price also does not necessarily correlate with a onetime refund - it is enough to recall the well-known scheme of payment by installments of the customer (portioned or phased payment). It is possible to imagine the cases when the amount of compensation is zero or even negative. So, for example, within the framework of advertising campaigns, a certain amount of commercial products is often simply donated, and in some cases, for example, within the framework of public testing, commercial products are assigned by the supplier to the customer formally and, in fact, with an additional payment (it is not entirely appropriate to discuss the additional encumbrances that arise here). Barter reimbursement schemes are also common. Accordingly, a conceptual interpretation problem arises - either to organize and implement a unified price representation, or create a unique management toolkit for each scheme. Therefore, the problem of correct interpretation of price

*Corresponding author: svgvgy@mail.ru 
management - as local or capable of universalizing all compensation schemes - is quite relevant and seems to have not yet been resolved either in practice or in theory.

\section{Materials and methods}

A characteristic of any market economy is a one-time or systematic production of some identical or diverse marketable product, which is then reassigned by the supplier of marketable products to its customer for a certain one-link or multi-link chain of involved subjects.

Any high-tech enterprise supplies something and acquires something, at least in the form of products and material and technical services, as well as R\&D results. Let's mention that the phenomenon of natural high-tech production can exist as an abstract phenomenon.

Of course, the global construction of the system of property relations similar to the scheme introduced, for example, in [1-2], is most likely complicated. However, in all cases, assignable commercial products and compensation for them are highlighted, although, the positioning of these objects is generally seen as conditional - a clear example of this convention is clearly visible in barter.

At the same time, the most "left" subject in the supply chain is the manufacturer (in the broadest sense) of the marketable product, and the right one in the chain of customers is its "consumer", also in the broadest sense. Naturally, "customer and consumer" are not synonymous concepts in the sense of the word.

Note that in terms of content, the production and consumption of marketable products are very often understood rather primitively. The manufacturer is considered to carry out some kind of production and technological activity, and the consumer is recognized as using these commercial products to provide or derive some benefit for themselves. At the same time, in practice, numerous situations are known when a manufacturer of a commercial product does not actually produce it, does not take purposeful physical actions, is inactive - for example, he somehow discovers it, and sometimes he has it even without his will. In the same way, not everything is obvious with the consumer - for example, the consumption of marketable products can be absolutely passive. It can simply be stored by the consumer or even destroyed by the consumer. In this case, the utility of marketable products for the consumer turns out to be completely non-trivial. Therefore, the concepts of production and consumption are more likely not semantic, but, first of all, positioning the status of the subject in the list or chain of its counterparties.

Thus, in the general case, there is a chain (this term is used in theoretical schemes and in practice more often in relation to persons, to subjects of legal relations, rather than a list) of some subjects of legal relations: $\boldsymbol{S}_{\boldsymbol{1}}, \ldots, \boldsymbol{S}_{\boldsymbol{n}} \ldots$, and it is known that $\boldsymbol{n}>\boldsymbol{1}$. And a situation when $\boldsymbol{n} \rightarrow+\infty$ is quite possible (for example, when the final customer is unknown and any subject of legal relations can become one an unlimited number of times). Here, the case when the subject of legal relations produces commercial products for their own needs is not considered (for example, as is the case when performing the so-called search and back-end R\&D), because Russian legislation (Civil Code of the Russian Federation) does not provide for the option when the supplier and the customer of marketable products - one and the same person. By the way, the Tax Code of the Russian Federation also does not consider this kind of manipulation. Therefore, it seems inadmissible to go beyond the framework of the current legislation even in the interests of globalization of abstract conceptual schemes.

Accordingly: $\boldsymbol{S}_{\boldsymbol{1}}$ - a manufacturer, $\boldsymbol{S}_{\boldsymbol{n}}$-a consumer, $\boldsymbol{S}_{1}, \ldots, \boldsymbol{S}_{\boldsymbol{n}-1}$-suppliers, and $\boldsymbol{S}_{2}, \ldots, \boldsymbol{S}_{\boldsymbol{n}}$ - customers of commercial products. Of course, in the general case, this chain is branching, bifurcational (a visual analogue of a chain reaction known in nuclear physics with one starting point appears), especially if lots of commercial products are allocated - first, for example, an exclusive sale is allocated, then a wholesale, then - small wholesale, then - retail. However, 
for the outlined schemes, this is completely insignificant - it is enough to trace at least one, completely arbitrary chain of subjects of legal relations for one elementary unit of commodity output.

Moreover, for each pair of subjects $\left\{S_{i}, S_{i+1} ; \boldsymbol{i} \in[1, n-1]\right\}$, a contract of a compensated assignment of a certain object of marketable output is to be concluded. Note that what has been described does not depend on the type of property right under which the product is transferred. Therefore, for the sake of brevity, further we will assume that the assignment is made in the context of property rights in any of the seven known combinations of its components - the rights of ownership, use and disposal. The agreement is bilateral.

\section{Results}

An obvious question arises about the specification of the contractual scheme for the assignment of commercial products. It is a known fact that a commercial product can be assigned in an unlimited number of contractually established ways - both well-known, traditional, and newly formed ones. According to the current Civil Code of the Russian Federation, the variety of contracts for the assignment of property rights is open, and contractors have the right to freely enter a new type of contract or use a known one. However, despite this absolutization of freedoms, legislation requires mandatory determination of the amount of compensation, although in a somewhat incorrect form of the requirement to establish the contract price.

The most common contracts for the assignment of commercial products are contracts for the supply, purchase and sale, donation, barter. Contracts for the performance of R\&D and technical work are, in fact, also within the meaning of contracts for the delivery of the results of work, because their performer is required to produce results for the customer, and not the very fact of performing the work.

However, in all cases, the contract for the assignment of commercial products must exist. The question of its form and obligatory registration, etc. is separate. Therefore, for the sake of definiteness, we will mainly operate with the term "supply agreement".

The specific localization of marketable products can also be excluded from the schemes. The Civil Code of the Russian Federation defines open the variety of objects of property law available for free expansion by the subjects of legal relations, although it defines a fairly large number of typical types of property objects - see, for example, systematization in [2].

The most common are the following terminological interpretations of the "price-like" characteristics of refunds:

- price as the cost equivalent of the customer's compensation to the supplier for a material object, right, security, intellectual property, etc. It is inappropriate to consider here a wide variety of prices, because the methods of pricing in no way affect the schemes under discussion;

- tariff as the cost equivalent of the customer's refund to the supplier for the provided service;

- the type and amount of barter compensation as a material equivalent of the customer's compensation to the supplier for commercial products. In this case, the uncertainty is especially high: where is the commercial product, and where is the compensation. Undoubtedly, barter transactions may imply the interpretation of the exchanged objects not as values, but as use values. But the results of barter transactions should still be recorded in value equivalents;

- the amount of deductive compensation as a certain share assignment of the customer to the supplier from the financial and economic results of its activities in value terms - for example, the share of generated net profit. Such schemes are common in the field of operating with franchises and in the so-called Islamic banking sector, when instead of the 
interest rate, the share of the borrower's net profit transferred to the lender is often determined. It should be noted that in this case, the value equivalent of compensation is determined not a priori, as in previous cases, but a posteriori. Of course, such restrictions as "such a percentage of the customer's profit, but not less than so many monetary units" can be introduced. Options and barter deductions are known - for example, as is often observed during harvesting ("every tenth basket - to the collector").

A separate question is whether to refer to the price management regulation on the establishment of price characteristics that can be introduced by:

- legislative norms (nowadays, there seem to be no such restrictions, because the Civil Code of the Russian Federation proclaimed freedom of contract prices, although the same federal laws on state contracting introduced significant restrictive regulations);

- federal general legal documents;

- verdicts of the antimonopoly authorities;

- decisions of the judicial authorities;

- decisions of the tax authorities, which now establish a framework for price variability for the case of affiliated entities, for example, those included in corporate groupings of a holding type;

- constituent documents of subjects of legal relations - primarily legal entities;

- the regulations of the conducted competitions (tenders) and auctions.

This is also price management, but only external price management, management from the environment external in relation to the counterparty. And the very setting of prices is an internal, counterparty management.

The compensations themselves are either monetary funds or other objects of other types of property, and more broadly - property rights. However, in modern Russian conditions, non-monetary forms of compensation for marketable products give rise to almost insoluble tax problems. Therefore, all refunds will be quantified in value terms. In cases of a barter scheme and a deduction scheme with in-kind contributions, such an assessment will be exclusively calculated, since the documented receipts of funds will not be made.

Refunds with a price-like form and a $\boldsymbol{C}\left(t_{i j}\right)$ value can be made only at some discrete points in time (formula 1):

$$
\left\{t_{i j} ; i \in[1, n-1] ; j \in[1, m]\right\},
$$

where $\boldsymbol{m}$ - the number of times such refunds are made.

For example, the mentioned discretization may be related to the organizational phenomenon of "banking days". The option of multiple transfer of monetary reimbursement within one minimum chronological period (for example, a day) looks too unusual to be considered separately. Although, formally no one bothers to consider an extraordinary flow of payments. Such clever tools are sometimes used in practice, when large transfers are distributed to simultaneous small payments.

In this case, the values of the broadly interpreted prices $\boldsymbol{C}\left(\boldsymbol{t}_{i j}\right)$ can have an arbitrary sign and an arbitrary size (unless, of course, we consider physical restrictions, such as the limits of available funds and the restrictions of common sense).

Then any reimbursement under the supply agreement for each pair of subjects "supplier - customer" $\left\{S_{i}, S_{i+1} ; \boldsymbol{i} \in[\mathbf{1}, \boldsymbol{n}-\mathbf{1}]\right\}$ will be presented in the following form in terms of value or equivalent (formula 2):

$$
\left\{C\left(t_{i j}\right), i \in[1, n-1] ; j \in[1, m]\right\} .
$$

In the most general case, indexing of the contract number, type of commercial product, its modification versions, etc. are added. 
Accordingly, it can be seen that the broadly interpreted price in its formalized presentation is almost identical to the stereotypically interpreted price. Only in the case of a stereotypically interpreted price, in fact, a particular, degenerate case is obtained: $\mathrm{m}=1$.

The introduced price interpretation is preferable for the following reasons:

- invariant in relation to the type of compensation characteristics;

- invariant in relation to the amount of compensation and the amount of compensation (currency of compensation);

- allows any changes (in terms of time, currency and size) when revising the price terms of the contract;

- can take into account all kinds of allowances, discounts, fines, penalties, fees, etc.

As a result, along the entire chain, there is a ribbon chart of payments-refunds.

Let us now consider how specialized management can be localized - price management in the area under consideration. Such localization is possible for various organizational and institutional levels of management, including the case of corporate groupings, such as Russian high-tech holdings.

It is well known that any management is characterized by:

- goals;

- management influences;

- external conditions;

- prohibitions on the degree of achievement of goals and management impacts;

- horizon (period) of management.

It can also be determined by other characteristics.

Accordingly, these factors are discriminating against various aspects and further - types of management.

Obviously, the goals of management for the case of an enterprise or holding company are universal for almost all types of specialized management.

The only thing that makes it possible to localize management in this case is the nature of management influences and, accordingly, management decisions. The rest of the signs make it possible to differentiate price management (for example, into strategic and tactical; into operational, short-term, medium-term and long-term; for conditions of monopolization and non-monopolization; into conventional and anti-crisis, etc.).

\section{Discussion}

Accordingly, price management is a management where price assignments in an expansive interpretation are used as management influences.

These prices relate to:

- commercial products purchased by the enterprise;

- commercial products supplied by the enterprise.

Thus, with competent price management, both marketing spheres are affected (see, for example, [3-6]) - "input" - in relation to production subcontractors, and "output" - in relation to customers of commercial products.

Therefore, in relation to a modern Russian high-tech holding, we will distinguish the following types of price management decisions:

- prices;

- price boundaries, which can be set with varying degrees of certainty of boundaries;

- regulated pricing procedures with varying degrees of prescription stringency.

As a rule, the first of the listed types of price management decisions is typical for all enterprises - members of a high-tech holding, the second and third - only for the holding company, which is also a structure manager. We note that, in accordance with Russian law, 
a holding company cannot directly set prices for commercial products of the holding companies. Although, of course, this prohibition can be quite easily and correctly got around.

\section{Conclusion}

Taking into account the above considerations, it seems reasonable to draw the following conclusions:

- nowadays, in the conditions of Russian economic realities, it is obligatory to reimburse the customer to the supplier for the delivered commodity products, regardless of its monetary or non-monetary nature, determined by the conditions of occurrence and the size of the contract concluded by them;

- the price characteristic of this compensation is multiple, but it is correctly reducible to a list (sequence) of sizes of one-time transfers of funds by the customer to the supplier at some discrete moments in time. This interpretation also takes into account the near-price terms of contracts (fines, penalties, fees, etc.), as well as revisions of the price terms of contracts;

- the values of these one-time transfers can be theoretically arbitrary, limited only by physical boundaries;

- stereotypical interpretation of the price of a commercial product is a special case of an expansive interpretation obtained by introducing the uniqueness of the moment of reimbursement transfer;

- specific variety of management is determined by a number of basic indicative characteristics of management, including the nature of management decisions;

- price management is defined as management within the framework of which management decisions are made and management influences on prices for commodity products are implemented in an extended interpretation.

\section{References}

1. T. V. Alesinskaya, D. V. Arutyunova, V. G. Orlova, I. V. Ilin, S. V. Shirokova, Conception BSC for investment support of port and industrial complexes Academy of Strategic Management Journal, 16(1), 10-20 (2017)

2. V. Ilin, A. V. Izotov, S. V. Shirokova, O. V. Rostova, A. I. Levina, Method of decision making support for it market analysis Proceedings of 2017 20th IEEE International Conference on Soft Computing and Measurements, SCM 2017, 7970732, 812-814 (2017)

3. S. Kalyazina, A. Borremans, A. Dubgorn, Participation of citizens in sustainable development of big cities, MATEC Web of Conferences, 193, 01029 (2018)

4. F. Aggogeri, A. Borboni, A. Merlo, N. Pellegrini, R. Ricatto, Materials 10(3), art. no. 297 (2017) DOI: 10.3390/ma10030297

5. F. Aggogeri, A. Avanzini, A. Borboni, S. Pandini, International Journal of Automation Technology 11(2), 311-321 (2017) DOI: 10.20965/ijat.2017.p0311

6. T. Zhang, Z. A. Shaikh, A. V. Yumashev, M. Chład, Applied model of E-learning in the framework of education for sustainable development. Sustainability (Switzerland), 12(16), art. no. 6420 (2020) doi: 10.3390/SU12166420 